\title{
Analysis of Financial Markets Integration of Iran Within the Middle East and with the Rest of the World
}

\author{
Parinaz Ezzati \\ Department of Business, Faculty of Economics, University of Western Australia, Australia
}

Received 2012-07-08, Revised 2012-07-16; Accepted 2013-10-10

\begin{abstract}
It is universally argued that Iran's financial markets are effectively isolated from the rest of the world. However, in the last three years, privatization increased in Iranian financial markets as well as capitalization, Foreign Direct Investment (FDI) and equity prices, albeit with suspicion of reaching the bubble level. Questions are raised whether Iran is still isolated from the rest of the world. To see whether argument in relation to isolation of Iranian financial markets is true and to better understand Iran's financial development, we estimate financial interdependencies of Iran within the Middle East and with the rest of the world based on the important recycling of petrodollars. For this analysis monthly financial data from equity, money and foreign exchange markets are applied over 12 years. Integration of each of these markets are analysed in turn for Iran within the region and with the rest of the world. Auto-Regressive Distributed Lag (ARDL) cointegration method is conducted to analyse the interdependencies among the financial markets after the application of unit root test in presence of structural breaks. We found that Iran has fairly independent and isolated foreign exchange market. However, its equity and money markets are integrated within the Middle East and with the rest of the world. Iran is neither completely segregated nor fully integrated with the rest of the world; it is still controversial whether Iran should be considered as a good choice for international portfolio diversification based on its segregated nature.
\end{abstract}

Keywords: Econometric Modelling-Financial Econometrics, International Financial Markets, Financial Integration, Iran

\section{INTRODUCTION}

Increasing global financial liberalization has important consequences for developing economies like Iran as it makes these economies more vulnerable to overseas financial shocks (e.g., the Asian Financial Crisis in 1997 and the Global Financial Crisis in 2009). Financial integration is a process through which one country's financial markets including money, equities, bonds and foreign exchange derivatives and bank assets become more closely integrated with other countries' financial markets.

There are a number of ways through which financial integration can be occurred. According to Elyasiani and
Zhao (2008), one way is trade in capital goods followed by equality of marginal product of capital among trading countries. Another way in their point of view is policy coordination which creates integration among world countries' financial markets, albeit indirectly. Some other ways from their perspective are speculative activities in currency markets, portfolio rebalancing and contagion across markets, ways of transferring shocks among the countries financial markets by enhancing the integration. In addition, Agenor (2003) believed the key factors underlying the process of financial integration is the matter of globalization coupled with investors looking for the higher rates of return and the prospect for global risk sharing and portfolio diversification. 
Moreover, Bekaert and Harvey (2002) Considered two stages for evolution of a country from segmented to integrated. They believed economic integration is achievable by removing barriers to trade of goods and services while financial integration needs unrestricted access by foreigners to domestic capital markets. Also Phylaktis and Ravazzolo (2005) argued that the abolition of foreign exchange controls on financial markets, developments in technology of communications and trading systems and innovative financial products such as country funds and American Depository Receipt (ADR) make more opportunities for global financial investments. Although, they believe such an indirect ways e.g., ADR and country fund may make some difficulties to measure the financial markets integration. Furthermore, (Yang et al., 2003; Bekaert et al., 2005) specified the financial integration among countries get enhanced over the period of economic crisis. Ultimately, $\mathrm{Yu}$ and Hassan (2008) indicated the large market capitalization is an important key to boost the financial integration.

The process of global financial integration started in the mid-1980s and got accelerated over the past decade; this is evident from the rising stocks of international assets and liabilities held by the countries around the world (Prasad, 2011). A review on previous literature shows that increasing global financial liberalization has been coupled with increasing the global attention to financial markets integration when policy makers and portfolio managers found emerging markets present diversification potentials not provided by more mature markets (Neaime, 2005). Financial integration may help to financially deepen an economy which allows entrepreneurs, firms and investors to access capital markets more easily in the country. Moreover, it could have technology spillovers and also it may make benefits via risk sharing. Risk sharing through portfolio diversification lowers exposure to overseas domestic risks. However, financial integration makes the economies vulnerable to global financial shocks. In other word, one of the consequences of financial integration is that financial market movements in one country can considerably affect financial market movements in another country. While, financial integration implies free capital movements across countries as well as closely substituted domestic assets for foreign assets.

Shin and Sohn (2006) investigated how deeper financial integration may affect price co-movements. They pointed to previous studies, assessing the degree of financial integration between economies by estimating the 'border effects' in which the border between two countries influences financial asset price interaction. The stronger border effects imply inefficient resources allocation among the countries and the border effects will decrease when financial integration deepens. Shin and Sohn (2006) Claimed financial integration enhances price co-movements as deeper financial integration implies the weaker arbitrage opportunity of trading financial assets and means quicker convergence of prices of assets. In view of that co-movements between financial asset prices (in the form of a cointegrating relationship) are considered as evidence of financial integration in this research, commonly used by previous research. It means that a greater co-movement in countries' financial asset prices is seen as a reflection of greater financial markets' integration among countries.

According to Iran's segregated nature, it is universally argued that Iran's financial markets are effectively insulated from the rest of the world. However, in the last three years privatization increased in Iranian financial market as well as capitalization, FDI and equity prices, albeit there is a suspicion of reaching the bubble level (IMF, 2011b). In addition, major focus of the government over its fourth and fifth development plans (2005-2015) has been expanding foreign trades, attending in international markets actively and increasing global integration. Moreover, Iran has received significant spillovers in recent years from neighbouring financial markets, mostly from Saudi Arabia (IMF, 2007). Also having a look at Iranian financial markets shows that Iranian financial markets have been suffering from financial uncertainty which can be caused by reflection of the presidential election and the negotiations on the nuclear program (IMF, 2011a). In addition, different sanctions (e.g., U.S. and United Nations Security Council (UNSC) sanctions) have been affecting Iranian financial transactions and international trade when they increase cost of business and restrict FDI and technology transfer. Importantly, one characteristic of Iran as a developing economy is its vulnerability to effects of shocks in general, meaning the consequential impairment can be extensive and it may linger on (Elyasiani and Zhao, 2008). Due to vulnerability of Iranian economy in the environment of increasing financial liberalization, this research aims to analyse Iran's integration within the Middle East and with the rest of the world in the important recycling of petro dollars to better understand Iran's financial development and provide information for policy makers and portfolio managers in order to set appropriate monetary policy in this environment of increasing financial liberalization.

Order of the remainder of this study is as follows. After criticizing of the previous literature, clarification of appropriate models and methods is discussed, followed 
by deliberating the data, choice of markets and countries. Ultimately, empirical results and summery and conclusion are reported to end the study.

Financial integration and the price linkages among financial markets have been widely analysed in previous works. Most of these analyses have selected some developed and developing countries and dominantly have focused on equity markets. A partial list of such work includes (Fadhlaoui et al., 2009; Yu and Hassan, 2008; Soofi, 2008; Elyasiani and Zhao, 2008; Neaime, 2005; Yang et al., 2003; Bessler and Yang, 2003; Yuhn, 1997). Notably, these studies have applied similar methods for their analysis. One of the common approaches applied in the literature for testing the financial integration is cointegration framework. Basically cointegration framework is to analyse interdependencies among variables which are not stationary. The procedure starts with testing the stationarity of variables. The stationarity of variables is tested commonly by traditional unit root methods viz., ADF and PP. The second step which is cointegration analysis is mostly conducted through Johanson and Joselious cointegration approach, based on the nonstationarity nature of price series, with the exception of (Marashdeh, 2005; Bakri et al., 2009; Bessler and Yang, 2003; Elyasiani and Zhao, 2008) which have applied other methods, these methods are discussed as follows.

Bessler and Yang (2003) used ECM and Direct Acyclic Graph (DAG) to examine the interdependencies and causality among markets, applied to make use of any Vector Auto Regressive (VAR) models representing multiple time series in terms of long-run, short-run and contemporaneous relationships. They have combined cointegration, error correction modelling, innovation accounting and directed acyclic graphs. They believe individual coefficients of ECM make difficulties for the short-run, dynamic, exploration as these coefficients are difficult to interpret. They claimed that the ECM is not suitable enough to explore about contemporaneous relationships among the variables, so they applied innovation accounting techniques for their analysis.

On the other hand, Elyasiani and Zhao (2008) applied generalized vector auto regression (GVAR), Generalized Impulse Response Function (GIRF) and Generalized Variance Decomposition (GVD). VAR framework can measure the degree of co-movements across the markets. GIRF shows the time outline of the inter market spillovers and verifies the speed of transmission of the shocks to find the durability of their effects in the markets. Also GVD analysis draws the shares of innovations in the selected countries. They claim that these techniques are not sensitive to the ordering of the countries and the more reliable results could be achieved than using the commonly used impulse response and variance decomposition methods.

Ultimately, (Marashdeh, 2005; Bakri et al., 2009) applied ARDL cointegration approach to analyse interdependencies among markets. Marashdeh (2005) is referring to Pesaran and Shin (1998) that appropriate modification of the orders of the ARDL model is adequate to instantaneously correct for residual serial correlation and the problem of endogenous regressors. Also Bakri et al. (2009) by referring to Pesaran et al., (2001) point out one of the important advantages of applying ARDL is not requiring pre-testing of variables for unit roots before proceeding to cointegration analysis when reliability of non-stationarity of variables is always questionable. Also he highlights sufficient number of lags applied by ARDL method to capture the datagenerating process in modelling framework.

In addition, previous studies have used mostly daily financial data, with the exception of some studies which have applied monthly data e.g., (Elyasiani and Zhao, 2008; Shin and Sohn, 2006; Marashdeh, 2005; Yuhn, 1997) and also some studies which have applied weekly financial data e.g., (Neaime, 2005; Bakri et al., 2009). It is argued that monthly data is less volatile than higher frequency data (e.g., daily and weekly), suitable to achieve a clearer picture of movements of the indices away from short-term fluctuations. Also in the previous literature monthly data is mostly suggested for emerging markets as they react to the world events slowly in contrast to developed markets which may choose the higher frequency data e.g., daily and weekly over the monthly.

According to results achieved by previous literature, there may not be a rule to confirm whether existence of the financial integration among countries depends on developed or developing characteristics of the nations. But generally part of the results of these studies imply on unidirectional effects from developed to developing countries. For example, Bessler and Yang (2003) declares that some developed markets are leading the other countries price movements considerably e.g., the U.S. equity market, while it is biased by own chronological and market innovations. Importantly, Elyasiani and Zhao (2008) (The methods applied for this research explained earlier in this section) imply that Tehran Stock Exchange (TSE) is a small operating market in the developing country with some considerable weaknesses. First, TSE is government control with significant authoritarian restrictions and lack of competition. Second, scarce of transparency and poor 
information distribution. Third, lack or rare trading of a large number of companies. Also they believe the theoretical models which are based on the efficient markets assumption like Capital Asset Pricing Model (CAPM) are not sufficient for the TSE data analysis and should be suitable for data driven procedures such as VAR and Variance Decomposition (VD). In the GVAR context, they found significant effects of past shocks on financial markets in the current situation. In addition in the context of GIRF, the own effects for emerging markets like Iran showed more power than cross country effects, while they found cross-country effects are durable (they linger after 3 months) for Iran, Germany and U.S.. Furthermore, according to GVD analysis, domestic shares played a significant role in all the selected countries when remained steady for 2 years after each shock. Also they found that domestic shares are larger in emerging countries e.g., Iran than in the industrialized countries. Ultimately, they concluded weak financial integration (in terms of equity market) for Iran with global financial market which may save Iran from effects of global shocks but prevent it from flow of money to get economic prosperity and growth. They indicated Iranian equity market is not a good choice for international portfolio diversification, in spite of its segregated nature. When the cost of capital in Iran is higher than the case if Iran was integrated with the global market and also there are many limitations in Iranian markets such as political, regulatory and technological obstacles.

We applied cointegration methods to analyse interdependencies among financial markets which requires analysing of stationarity of the series. Thus, to test the stationarity of the variables we applied unit root test in presence of breaks by (Lee and Strazicich, 2003; 2004) found as a suitable approach discussed in Section 3 of this study. Moreover, ARDL is chosen as a better suited cointegration method discussed in Section 3 of this study. Furthermore, reasoning's of application of monthly financial data is deliberated in Section 4 of this study. We found that, although Iran has fairly isolated foreign exchange market, its equity money markets are integrated within the Middle East and with the rest of the world. Weak financial integration may save Iran from effects of global shocks but prevents the flow of money into the country and stops generating economic prosperity and growth in Iran. Importantly, it is still controversial whether Iran should be considered as a good choice for international portfolio diversification based on its segregated nature.

\section{THEORIES AND METHODS}

In order to analyse significance of the selected countries' financial markets' interdependencies in terms of comovements of financial asset prices, various ways exist e.g., correlation coefficient and cointegration methods. The use of a correlation coefficient is the most obvious method. But, Goletti et al. (1995) pointed out the matter of spurious correlation (According to (Goletti et al., 1995) refer to some previous literatures, applying correlation coefficient for financial integration analysis among markets masks the presence of other synchronous factors, such as general price inflation, seasonality, population growth and procurement policy. In order to solve these kind of criticisms on applying correlation coefficient, the correlation of price differences is considered and interdependencies of price changes among markets is estimated. When, price change would largely eliminate common) by applying correlation coefficient and other problems related to the often nonstationary nature of the price series which will be solved by the cointegration analysis. Also cointegration analysis, found as a common method in the recent literature applied in the current research. The procedure of applying this method and all the other selected methods needed for processing it viz., unit root tests are illustrated and also clarified in the following sections.

\subsection{Unit-Root Approaches}

To test the stationarity of series, variety different types of unit root tests exists. Unit root test is a test of stationarity (or nonstationarity) which has become widely popular over the past several years, e.g., (Dickey and Fuller, 1979), augmented DF (ADF) and (Perron, 1988). For DF test, it is assumed that the error term is not auto-correlated. But for the case that $\mathrm{t} u$ is auto-correlated, the ADF, extended version of DF proposed by (Elliott et al., 1996), is more reliable. In the following model ADF test consists of estimating a regression where $Y_{t}$ is a dependent variable, a random walk with drift and lagged values of the dependent variable are added in the model:

$$
\Delta Y_{t}=\beta_{1}+\beta_{2} t+\delta Y_{t-1}+\sum_{i=1}^{m} \Delta Y_{t-1}+\varepsilon_{t}
$$

where, $\varepsilon_{t}$ is a pure white noise error term, also number of lagged difference terms is often determined empirically. Hypotheses and asymptotic distribution are the same as DF statistic where DF distribution defined as $\tau$ - statistic $=\hat{\delta} / \mathrm{SE}(\hat{\delta})$ in order to test the null and the alternative Hypotheses, $\delta=0$ and $\delta \prec 0$ respectively. 
In sum, an important assumption of the DF test is independent and identical distribution of the error term $\mathrm{u}_{\mathrm{t}}$. While ADF test by adding the lagged difference terms adjusts the DF test in order to take care of possible serial correlation in the error terms. Ultimately, another traditional unit root test is PP unit root test which uses nonparametric statistical methods in order to take care of the serial correlation in the error terms without adding lagged difference terms. Also the asymptotic distribution of the PP test is similar to ADF test statistic (Perron, 1988). Empirical results by applying these mentioned traditional unit root tests are reported and compared later in this study along with the other empirical results.

However, Perron (1989) argued that the ADF and PP tests in presence of structural breaks are biased toward the non-rejection of the null hypothesis, incorrectly indicating non-stationarity of series. Means in response to the mentioned criticism about the reliability of traditional unit root test's result, breaks should be considered in the model over the selected period of time. Example of some of the unit root methods where the structural breaks are considered endogenously and/or exogenously are e.g., (Narayan and Popp, 2010; Lee and Strazicich, 2003; Lumsdaine and Papell, 1997) where two endogenous breaks considered in the model; (Perron, 1997; Zivot and Andrews, 1992; Perron and Vogelsang, 1992; Lee and Strazicich, 2004) where one endogenous break considered in the model. Ultimately, multiple endogenous structural breaks on multiple time series data is a considerable approach proposed by (Bai and Perron, 2003).

Lee and Strazicich (2003) proposed the Lagrange multiplier unit root test with two endogenous breaks which allows breaks under the both hypotheses, null and alternative. They mentioned by applying this method, explicitly rejection of the null hypothesis emphasizes the trend stationery and break dates will be determined accurately. In their perspective, main reason in false rejection of the null hypothesis is related to incorrect capturing of break dates.

Lee and Strazicich (2003) criticized Zivot and Andrews (1992) unit root approach in terms of getting biased non-stationary result by just including one break in the model, means ignoring other major breaks affective on the result. Following that (Lumsdaine and Papell, 1997) extended that direction and included two structural breaks in their model. According to Lee and Strazicich (2003), Endogenous break test Approaches which allows no break (s) under the unit root null and derive their critical values accordingly e.g., ZA and LP (and other similar) present an alternative hypothesis which would be unit root with break (s) instead of stationarity. Means rejection of the null hypothesis would imply rejection of a unit root without breaks instead of rejection of a unit root per se in the mentioned situation. Nunes et al. (1997) and Lee and Strazicich (2001) provided evidence that by assuming no break under the null in endogenous break tests, the test statistic diverges in order to reject the unit root null significantly when the Data-Generating Process (DGP) is a unit root with break (s). As a solution to the mentioned matter as the above, (Lee and Strazicich, 2003) proposed a twobreak minimum Lagrange Multiplier (LM) unit root test in which the alternative hypothesis unambiguously implies trend stationarity. Their testing methodology is extended from the LM unit root test that was initially suggested in (Schmidt and Phillips, 1992). Lee and Strazicich (2003) unit root approach in presence of two structural breaks is applied in the current research (Lee and Strazicich, 2003) proposes a unit root test in presence of two structural breaks and (Lee and Strazicich, 2004) proposed a unit root test in presence of one structural break).

Following (Perron, 1989; Lee and Strazicich, 2003) distinguished three models for unit root test in present of structural breaks viz., A, B and C. Model A is named "Crash" allows for a break in level, model B allows for a break in trend slope named "Changing growth" and model $\mathrm{C}$ allows for a break in both level and trend. In the current research model $\mathrm{C}$ is used where breaks in the levels and slops are allowed under the both null (Note: the null, model (2), includes dummy variables, $\mathrm{B}_{\mathrm{jt}}$ ) and alternative hypotheses, nonstationarity and stationarity respectively.

The two-breaks LM unit root statistics is obtained from the following regression according to the LM principle Equation 2 and 3:

$\Delta y_{t}=\delta^{\prime} \Delta Z_{t}+\phi \tilde{S}_{t-1}+u_{t}$

Where:

$\tilde{S}_{t}=y_{t}-\tilde{\psi}_{x}-Z_{t} \tilde{\delta}_{t} \quad t=2, \ldots, T$

where, $\mathrm{t} Z$ is a vector of exogenous variables defined by the data generating process, $\tilde{\delta}_{t}$ is the vector of coefficients in the regression of $\Delta y_{t}$ on $\Delta Z_{t}$ ( $\Delta$ is difference operator), $\tilde{\psi}_{\mathrm{x}}=\mathrm{y}_{1}-\mathrm{Z}_{1} \tilde{\delta} \quad\left(\mathrm{y}_{1}\right.$ and $\mathrm{Z}_{1}$ are the first observations of $y_{t}$ and $Z_{t}$ respectively). Equivalent to Perron (1989) Model C which allows for a shift in intercept and change in trend slope under the null hypothesis is described as $Z_{t}=\left[1, t, D_{t} D_{t}\right]$ ' Equation 4: 
Where $\left\{\begin{array}{l}D T_{j t}=t-T_{B j} \text { if } f_{t} \geq T_{B j}+1 \\ D T_{j t}=0 \quad \text { otherewise }\end{array} \quad j=1,2\right.$

Notably testing regression (2) involves using $\Delta Z_{t}$ instead of $Z_{t}$. Where $\Delta Z_{t}$ is described as $\left[1, B_{t}, D_{t}\right]$ and $B_{t}$ $=\Delta D_{t}$ and $D_{t}=\Delta T D_{t}$ then $B_{t}$ and $D_{t}$ correspond to a change in the intercept and trend under the alternative and one period jump and a change in drift under the null hypothesis respectively.

The unit root null hypothesis, $\phi=0$, is described in Equation 1 and the LM t-test is given by $\tilde{\tau}=t$-statistic testing the null hypothesis $\phi=0$. The augmented terms, $\Delta \tilde{S}_{t-j}$, are included to correct for serial correlation, where $j=1, \ldots ., k$.

Location of the break, $\mathrm{T}_{\mathrm{B}}$ will be determined endogenously through the LM unit root searches for all possible break points for the minimum t-test statistic as follows: $\operatorname{Ln} \tilde{\tau}(\tilde{\lambda})=\operatorname{In} f_{\lambda} \tilde{\tau}(\lambda) ; \lambda=T_{B} / T$. Table of results are reported quantitatively later in this study.

After testing stationarity of the series, the next step is applying cointegration method explained in the following subsection 2.2.

\subsection{Cointegration Approaches}

In the light of cointegration definition, regression of a nonstationary time series on another nonstationary time series may cause a spurious regression. But spurious regression may not be a problem as it is possible that two $I$ (1) time series will have the same stochastic trend in which case they are said to be cointegrated e.g., if, $X_{t}, Y_{t}$ $\sim I$ (1) then $u_{t}=Y_{t}-\beta_{1}-\beta_{2} X_{t}$ is generally $I(1)$, but is $I(0)$ if $X_{t}$ and $Y_{t}$ are cointegrated. Means the linear combination of random walk series cancels out the stochastic trends in the two series, in this case two series are cointegrated. In the mentioned context long-run relationship exists between $X_{t}$ and $Y_{t}$ and since $u_{t} \sim I(0)$, it is meanreverting to 0 so $Y_{t}$ reverts to $\beta_{1}+\beta_{2} X_{t}$ which gives the long-run relationship of $y_{t}=\beta_{1}+\beta_{2} X_{t}$, In this sense cointegration is said to imply a long-run relationship (The definition of cointegration can easily be extended to series which are integrated of a different order than 1).

Frequently used methods for cointegration tests are residual based like cointegration test of (Engle and Granger, 1987) and maximum likelihood based such as Johansen (1988) (you may look at (Johansen and Joselious, 1990) and (Johansen, 1991; 1995) as well). Moreover, some cointegration tests such as Gregory and
Hansen (1996) and Saikkonen and Lutkepohl (2000a) Refer to the three cited articles of (Saikkonen and Lutkepohl, 2000a; 2000b; 2000c) consider structural breaks. In the current research rather than using the common Johansen (1988) cointegration approach, the Auto-Regressive Distributed Lag (ARDL) method proposed by Pesaran and Pesaran (1997) is used since it is better suited to testing when variables are integrated of mixed orders (One of the most important reasons that caused the author to choose the ARDL cointegration method is based on the mixed order integrated series found by applying unit root test (results are discussed later in this study along with all other empirical results). The ARDL modeling approach is expanded by (Pesaran et al., 1996; 2001; Pesaran, 1997; Pesaran and Pesaran, 1997; 2009; Pesaran and Smith, 1998; Pesaran and Shin, 1998). The existence of the long-run and the short-run relations between the variables are tested by applying ARDL method.

According to Pesaran and Pesaran (2009), the augmented ARDL ( $\left.p, \mathrm{q}_{1}, \mathrm{q}_{2}, \ldots, \mathrm{q}_{\mathrm{k}}\right)$ model is as follows Equation 5-7:

$\phi(L, P) y_{t}=\alpha_{0}+\sum_{i=1}^{k} \beta_{i}\left(L, q_{i}\right) x_{i t}+\delta^{\prime} w_{t}+U_{t}$,

Where:

$\phi(L, P)=1-\phi_{1} L-\phi_{2} L_{2}-\ldots-\phi_{P} L_{P}$

And where:

$\beta_{i}\left(L, q_{i}\right)=\beta_{i 0}+\beta_{i 1} L+\ldots+\beta_{i q i} L^{q i} \quad i=1,2, \ldots, k$

where, cointegration of set of variables $y_{t}, x_{1 t}, \ldots, x_{k t}$ are considered by using models introduced through (5), (6) and (7) where $y_{t}$ has been arbitrarily selected as the dependent variable in (5) model (As explained below, the standard ARDL approach repeats the estimation of (5) with each of $x_{1 t}, \ldots, x_{k t}$ as the dependent variable in turn). L is a lag operator, $L y_{t}=y t_{-1}$ and $w_{t}, s \times 1$, is vector of deterministic variables such as intercept, time trend, dummy variables or exogenous variables with fixed lags. Lag length needs to be chosen before applying OLS to estimate the model (5), max lag length will be chosen on basis of sample size.

We will search over all possible combinations of $p$, $\mathrm{q}_{i}$ and choose maximum lag length depending on sample size. 
Next, model (5) will be estimated by OLS method for all possible values of $p=0,1,2, \ldots, m, q_{i}=0,1,2, \ldots, m, I$ $=1,2, \ldots, \mathrm{k}$ (optimal lag will be chosen through applying Akaike Information Criterion (AIC) or $\mathrm{S}$ chwarz Bayesian Criterion (SBC)); a total of $(\mathrm{m}+1)^{k+1}$ different ARDL models for maximum lag length of $\mathrm{m}$.

Notably, according to Pesaran and Pesaran (2009), values of criterion function can be computed by (Akaike, 1973; 1974; Schwarz, 1978; Hannan and Quinn, 1979) or single equation estimated model. According to Pesaran and Smith (1985), AIC, among other models, is one of the popular models selection criteria which suits the current research, considering the objectives and the selected sample size.

Next, the long-run coefficients and their asymptotic standard errors for the selected ARDL model will be computed.

Computed long-run coefficients for the response of $y_{t}$ to a unit change in $\mathrm{x}_{\mathrm{it}}$ are computed by Equation 8:

$\hat{\theta}_{i}=\frac{\hat{\beta}_{i}\left(1, \hat{q}_{i}\right)}{\hat{\phi}(1, \hat{P})}=\frac{\hat{\beta}_{i 0}+\hat{\beta}_{i 1}=\ldots=\hat{\beta}_{i q i}}{1-\hat{\phi}_{1}-\hat{\phi}_{2}-\ldots-\hat{\phi}_{\hat{P}}} \quad i=1,2 \ldots, k$

where, $\hat{\beta}_{i \hat{q}}, \hat{\phi}_{\hat{p}}$ are estimated from model (25) and $\hat{\mathrm{q}}_{\mathrm{i}}$ and $\hat{\mathrm{p}}$ are chosen values of $\mathrm{q}_{\mathrm{i}}$ and $\mathrm{p}$. Likewise, the long-run coefficients related to the deterministic or exogenous variables with fixed lags are computed by Equation 9:

$\hat{\psi}=\frac{\hat{\delta}\left(\hat{P}, \hat{q}_{1}, \hat{q}_{2}, \ldots, \hat{q}_{k}\right)}{1-\hat{\phi}_{1}-\hat{\phi}_{2}-\ldots-\hat{\phi}_{\hat{P}}}$

where, $\hat{\delta}\left(\hat{p}, \hat{q}_{1}, \hat{q}_{2}, \ldots, \hat{q}_{k}\right)$ is the OLS estimation of $\delta$ for the selected ARDL model.

Equation (5) can also be written in ECM form (Equation 15) and the ARDL procedure typically computes estimated coefficients of the ECM corresponding to equation (5). ECM provides information about the significance of the variables in the cointegrating relationship as well as the nature of the short-run adjustment mechanisms.

The ECM associated with the ARDL $\left(\hat{p}, \hat{q}_{1}, \hat{q}_{2}, \ldots, \hat{q}_{k}\right)$ is obtained from model (5) by using the following Equation 10-14:

$$
\begin{aligned}
& Y_{t}=\Delta Y_{t}+Y_{t-1} \\
& Y_{t-s}=Y_{t-1}-\sum_{j=1}^{S-1} \Delta Y_{t-j} \quad S=1,2, \ldots, P
\end{aligned}
$$

$$
W_{t}=\Delta W_{t}+W_{t-1}
$$

Likewise, $x_{i t}=\Delta x_{i t}+x_{i, t-1}$

$x_{i, t-s}=x_{i, t-1}-\sum_{j=1}^{s-1} \Delta x_{i, t-j} \quad s=1,2 \ldots, q_{i}$

By substituting the relations (10)-(14) in to model (5), we will have Equation 15 and 16:

$$
\begin{aligned}
& \Delta Y_{t}=-\phi(1, \hat{p}) E C_{t-1}+\sum_{i=1}^{k} \beta_{i 0} \Delta x_{i t} \\
& +\delta^{\prime} \Delta W_{t}-\sum_{j=1}^{\hat{p}-1} \phi^{*}{ }_{j} \Delta y_{t-j}-\sum_{i=1}^{k} \sum_{j=1}^{\hat{q} i-1} \beta^{*}{ }_{i j} \Delta x_{i, t-j}+u_{t}
\end{aligned}
$$

Where:

$$
\phi(1, \hat{p})=1-\hat{\phi}_{1}-\hat{\phi}_{2}-\ldots-\hat{\phi}_{\hat{p}}
$$

Measures the quantitative importance of the errorcorrection term. Moreover, $\phi_{j}^{*}$ and $\beta_{i j}^{*}$ are related to the short-run dynamics of the model's convergence to equilibrium.

The error-correction term, $\mathrm{EC}_{\mathrm{t}}$, can be written as follows Equation 17:

$E C_{t}=y_{t}-\sum_{i-1}^{k} \hat{\theta}_{i} x_{i t}-\hat{\psi}^{\prime} w_{t}$

$\hat{\theta}_{i}$ and $\hat{\psi}$ in model (17) are already computed by relations (8) and (9) explained earlier.

The hypothesis of 'non-existence of the long-run relationship' is defined as $H_{0}: \theta_{1}=\theta_{2}=\ldots=\theta_{i}=0$ and the alternative is $H_{1}: \theta_{1} \neq 0$ and $\theta_{2} \neq 0, \ldots, \theta_{i} \neq 0$ (In practice the test is carried out equivalently within the context of a "Conditional ECM", see (Pesaran et al., (2001)).

Mentioned hypotheses will be tested by the ARDL test statistic, asymptotic distribution of non-standard Fstatistic (irrespective of order of the integration of the regressors).

Appropriate critical values for the test statistic are tabulated by (Pesaran et al., 1996) for different numbers of regressors and ARDL models containing an intercept and/or trend. ARDL approach provides band covering, means if the computed F-statistic falls within the critical value band, the result of inference would reported as 
inconclusive and when is higher than the upper bound of $95 \%$ would be reported as significant refer to null hypothesis (more details are provided in section 4). In the case where Fstatistic is found significant, the ECM can also be used to test the significance of the longrun coefficients as well as the stability of the long-run equilibrium and if F-statistic is not significant means there is no level effects among variables, hence it is assumed that in this case analysis of the long-run and the short-run effects is not necessary.

The most popular advantage of ARDL is that it is independent of order of integration of the series (Pesaran and Pesaran 1997). In particular it is applicable when some variables are $\mathrm{I}(0)$ and others are $\mathrm{I}(1)$. This is the most important advantage of this method given the unreliability of standard stationarity tests (Pesaran, 1997). The necessity of having all the variables integrated of the same order in some methods such as the Johansen cointegration approach bring in a further degree of uncertainty in analyses of levels relationships (Pesaran et al., 2001). Mentioned earlier, the series in this study are found to be integrated of the different orders, $\mathrm{I}(0)$ and $\mathrm{I}(1)$, which makes the ARDL more suitable for the current study (ARDL approach identifies a relationship between a dependent variable and a set of regressors, suitable for the current research since the objective is to analyse whether there is any long-run relationship among the selected financial markets irrespective of the number of the relationships that could be answered by Johansen multiple cointegration relationships approach (this is not focus of this research)).

In conclusion, refer to the earlier discussion in this study, it is believed that financial integration enhances price co-movements when deeper financial integration implies the weaker arbitrage opportunity of trading financial assets, means quicker convergence of prices of assets. Co-movements between financial asset prices (in the form of a cointegrating relationship) are considered as evidence of financial integration dominantly used by previous literature. Means that co-movement among countries' financial asset prices is seen as a reflection of financial markets' integration among countries. Financial integration and the price linkages among the selected countries' financial markets are analyzed through ARDL method based on the procedure illustrated earlier. While, basically cointegration framework is to analyze interdependencies among variables which are not stationary. Based on the ARDL procedure, long-run interactions among the selected countries' financial markets will be estimated and stability of the long-run equilibrium in these markets after receiving effects from their own market and/or from overseas will be analyzed by considering the long-run effects and the VEC modeling.

In Section 3, data, choice of markets and the selected countries are discussed before going to the discussion of the empirical results.

\section{DATA, CHOICE OF FINANCIAL MARKETS, CHOICE OF COUNTRIES}

Monthly financial data from financial markets namely (equity, money, foreign exchange markets) over the period Feb-1997 to Dec-2009 (with the exception of money market which is analysed over the period Oct2003 to Dec-2009) (This limitation is imposed regarding the availability of data for Iran money market) is used in this research. The selected financial indices for the mentioned financial markets are equity price index (Equity price indices: "Indices shown for Share Prices generally relate to common shares of companies traded on national or foreign stock exchanges. Monthly indices are obtained as simple arithmetic averages of the daily or weekly indices, although in some cases midmonth or end-of-month quotations are included. All reported indices are adjusted for changes in quoted nominal capital of companies. Indices are, in general, baseweighted arithmetic averages with market value of outstanding shares as weights." (IMF-IFS introduction P xx) *Iran:"Weights reference period: 1990-1991 average. Data cover all companies listed in Tehran Stock Exchange and are produced as a Laspeyres-type index based on average daily prices" (IMF-monthly notes). *Saudi Arabia: "Share Prices (End of Period): Domestic Share Index covering agriculture, cement, electricity, other industry, banking and other services, base 1985" (IMF-monthly notes). *U.S.: "Market capitalizationweighted index covering domestic and internationalbased common stocks, ordinary shares, American Depository Receipts (ADRs), shares of beneficial interest, REITs, base February 5, 1971, Tracking Stocks and Limited Partnerships and excluding exchange traded funds, structured products, convertible debentures, rights, units, warrants and preferred issues" (IMFmonthly notes). *Germany:"Share Prices (End of Period): Share price index, base December 30, 1987, refers to the CDAX share price index (previously called all-share price index FWBX) of the Deutsche Börse A.G. 
It shows average price movements of all ordinary and preference shares officially listed on the Frankfurt stock exchange of companies with headquarters in Germany" (IMFmonthly notes)), short-run interest rate-deposit rate on money (Short-run interest rate-deposit rate on money: "Data refer to weighted average provisional rate of profits from non-public sectors' deposits with stateowned banks. The rate is weighted by the outstanding amount of the aforementioned deposits at the end of the reference period' (IMF-monthly notes). *Iran: "Data refer to weighted average provisional rate of profits from non-public sectors' deposits with state-owned banks. The rate is weighted by the outstanding amount of the aforementioned deposits at the end of the reference period' (IMF-monthly notes). *Saudi Arabia: "Deposit Rate: Simple average of daily interest rates on threemonth deposits" (IMF-monthly notes). *Germany: "Deposit Rate: Rate on three-month deposits in denominations of less than five hundred thousand euro" (IMFmonthly notes). *Japan: "Deposit Rate: Average interest rate on unregulated three-month time deposits, ranging in size from three million yen to under ten million yen" (IMF-monthly notes)) and nominal effective exchange rate (Nominal effective exchange rate: A real effective exchange rate index represents a nominal effective exchange rate index adjusted for relative movements in national price or cost indicators of the home country, selected countries ("The country compositions of the world and its subgroups are by in large aligned with those published in the IMF's World Economic Outlook (WEO). Note that some economies are not included in the WEO exercise, but report data to IFS; they are included in the IFS groups." (IMF-IFS P $\mathrm{XXv})$ ) and the euro area (IMF-IFS introduction $\mathrm{P}$ viii). *Iran: "Official Rate: (End of Period and Period Average): The exchange rate system is based on a dual official exchange rate structure; the floating rate and the export rate. The floating rate applies mainly to the imports of essential goods and the export rate applies to all other transactions. Beginning in March 1993, the exchange rate refers to the official floating rate. Prior to that date, the exchange rate referred to the basic official exchange rate of the Iranian Rial, which was pegged to the SDR. Beginning from March 2002, a unified exchange rate, determined at the inter-bank foreign exchange market, has replaced the dual foreign exchange rate system" (IMF-monthly notes). *Kuwait: The nominal effective exchange rate for Kuwait is not available, so the real exchange rate is used which is inverted to Dinar / $\$$ US, when it is available as \$US/ Dinar in IMF-IFS) respectively. All data are collected from IMF-International Financial Statistics (IFS) available online through dXtime (time series data management) software.

The selected financial markets (namely, equities, money and foreign exchange) are the important global financial markets viz., equity, money and foreign exchange for which data is available for all the selected countries. Also the selected markets are the main available financial markets which are likely to be important for the analysis of Iranian monetary policy in the current domestic and global financial atmosphere.

Moreover, monthly financial data is used following (Elyasiani and Zhao, 2008; Shin and Sohn, 2006; Marashdeh, 2005; Yuhn, 1997). It is argued that this type of data is less volatile than higher frequency data e.g., daily and weekly and therefore more suited to the current research framework. However, the possible drawback of using this type of data is that some of the interaction effects may be masked as they may be completed within the month. Thus, the dynamics caused by monthly frequency data may be underestimated interdependencies among the countries (Elyasiani and Zhao, 2008). Marashdeh (2005) claimed monthly financial data is appropriate to avoid biases common in weekly and daily data arising from non-trading and nonsynchronous trading with the consequence of achieving a clearer picture of movements of the indices away from shortterm fluctuations. Also according to Elyasiani and Zhao (2008), there are sufficient reasoning's which prove the using of the monthly financial data as a more suitable type for analyzing purposes for Iran. First, as mentioned earlier, monthly data is less subject to noise than higher frequency type. Second, most of the firms listed in Tehran Stock Exchange (TSE) market show highly infrequent training, means stock of some firms may not be traded for a month which shows that the higher frequency data such as daily data is not suitable to be considered in this situation. Importantly, emerging markets such as the TSE react to the world events slowly which confirms that the lower frequency data is more suitable for analysis.

Ultimately, the choice of countries for this research is based on important recycling of petrodollar since according to the bulk of funds flowing around the world, the strongest global financial integrations are expected to be found among the biggest oil exporters e.g., Iran, Saudi Arabia and Kuwait, representing the Middle East and 
their major importer countries e.g., U.S., Germany and Japan, representing the rest of the world. Although it is not clear where these funds have been invested, some previous research indicated most of the petrodollars have been invested outside the Middle East region, mostly in North America and Western Europe (El-Gamal and Jaff, 2008). There is some evidence that the bulk has ended up in the United States, directly or indirectly (Higgins et al., 2006). Importantly, the selected oil exporter countries are the biggest holders of net foreign assets and they contain the highest surpluses in the world (IMF 2007). Also the mentioned major oil importer countries' financial markets are sophisticated in terms of the large size of their global capital markets in the world and in terms of selected financial indicators such as GDP, total official reserves, bonds, equities, bank assets and exchange market derivatives (for quantitative details Jackson, 2008). After application of the data by using the methods explained earlier, empirical results are reported in Section 4.

\section{EMPIRICAL RESULTS}

\subsection{Empirical Results of Unit Root Test Analysis}

Empirical results by applying the traditional unit root tests viz., ADF and PP methods show all the series are I(1), with the exception of Germany in terms of time series of deposit rate-interest rate on money which is I(2), integrated of order two. Previous literatures by applying mostly traditional unit root tests viz., ADF and PP (Yuhn, 1997; Yang et al., 2003; Elyasiani and Zhao, 2008; Fadhlaoui et al. (2009) mostly have found nonstationary equity price series for the U.S., Germany and Japan similar to the results achieved in the current research. Also Neaime (2005) and Yu and Hassan (2008) eported the same result for Saudi Arabia and also Neaime (2005) informed non-stationary series for Kuwait similar to other selected countries in the current research. Furthermore, Elyasiani and Zhao (2008) stated nonstationarity of Iranian stock price indices integrated of order one, I(1).

We apply Lee and Strazicich (2003) test to equity price indices; results are reported in Table 1. In the table for each variable, $\mathrm{S}_{\mathrm{t}-1}$ gives the minimum Lagrange Multiplier test statistic (LM statistic) and $\mathrm{T}_{\mathrm{B} 1}$ and $\mathrm{T}_{\mathrm{B} 2}$ in the next two columns of the table give the break dates where $t$ statistic is reported for dummy variables considering both the level and trend breaks and on the basis of significance of the trend variable we conclude whether there is a unit root with breaks or not. The results indicate non-stationary of all the stock price index series with two significant breaks (As it is explained in the method part, the unit root test which allows two breaks in both intercept and trend is conducted. Complexity of the results about significance of one break date in both intercept and trend at the same time, made us to consider the significance of the breaks in terms of trends) with the exception of Saudi Arabia which shows stationary with two significant breaks and Japan which indicates unit root with just one significant break over the selected period of time. See the results reported quantitatively for Iran in the Table 1 which is just clarified for other selected countries that will be provided quantitatively upon request.

Also, we found exchange rate series all as nonstationary with two significant breaks with the exception of Kuwait and United States which are stationary, See the results reported quantitatively for Iran in the Table 2 which is just clarified for other selected countries that will be provided quantitatively upon request.

Ultimately, interest rate series show stationary with two significant breaks for all the selected countries with the exception of Saudi Arabia which shows stationary with one significant break, See the results reported quantitatively for Iran in the Table 3 which is just clarified for other selected countries that will be provided quantitatively upon request.

The second step as explained earlier in this study is applying the ARDL cointegration method which we set out earlier in this chapter. The model and the empirical results are explained and reported in the following subsection.

\subsection{Empirical Results-Cointegration Analysis}

According to the suitability of the ARDL approach for this research discussed earlier in this study, this method is applied for the current research. ARDL cointegration analysis has determined the significance of financial market integration in terms of the 'law of one (cointegrating vector of) price' as used by Wilson and Marashdeh (2007). ARDL method is applied to assess interdependencies among the financial markets in the Middle East (namely Iran, Saudi Arabia and Kuwait) and the rest of the world (namely US, Germany and Japan). Before reporting the empirical results, the structure of the estimated models in the current research is designed as follows Equation 18: 
Table 1. Unit root test for stock price indices according to Lee and Strazicich $(2003 ; 2004)$ Two-Break (break in both intercept and trend)

\begin{tabular}{|c|c|c|c|c|c|c|}
\hline Variable & $\begin{array}{l}\mathrm{S}_{\mathrm{t}-1} \\
\text { (LM test statistic) }\end{array}$ & $\mathrm{T}_{\mathrm{B} 1}$ & $\mathrm{~T}_{\mathrm{B} 2}$ & & $\mathrm{k}$ & Result \\
\hline Stock price indices for Iran & $A u g-$ & $99\left(\frac{T_{B_{1}}}{N}=\lambda_{1}=0.205\right)$ & $D e c-9$ & $\left.\lambda_{2}=0.615\right)$ & 1 & Unit root with \\
\hline$\left(\mathrm{P}_{\mathrm{It}}\right)$ & $\begin{array}{l}\mathrm{B} 1(\mathrm{t}) \\
0.0330\end{array}$ & $\begin{array}{l}\mathrm{D} 1(\mathrm{t}) \\
4.8423 * * *\end{array}$ & $\begin{array}{l}\mathrm{B} 2(\mathrm{t}) \\
0.2730\end{array}$ & $\begin{array}{l}\mathrm{D} 2(\mathrm{t}) \\
-6.4625 * * *\end{array}$ & & Two breaks \\
\hline
\end{tabular}

- B1(t): Break in intercept

- D1(t): Break in trend

- All the series are in natural logs

- Monthly data series are applied over the period of Jan-1997 to Dec-2009

- The applied model is the model with two breaks in both intercept and trend

- This test is applied with maximum lag which is $k=12$, suitable when monthly data is applied (Hall, 1994) The significance of break dates are assessed by $* * * 1 \%, * * 5 \%$ and $* 10 \%$ critical values of T-Ratio. Significance of the break points Will be generally tested at the $\mathrm{t}_{0.05}$-statistical critical value. Source: IMF-IFS and author calculations

- The model $\mathrm{C}$ which allows the break in both intercept and trend is applied due to the fact that all variables in this study have trend. To accept the significance of the break dates, the t-stat of breaks for trends are considered when the complexity of the results in terms of significant break dates in both intercept and trend made us to put this limitation on our decisions) minimum LM Unit-Root Test Source: The author's calculations

Table 2. Unit root test for Exchange rates according to Lee and Strazicich (2003; 2004) Two-Break (break in both intercept and trend) minimum LM Unit-Root Test

\begin{tabular}{lllllll}
\hline & $\mathrm{S}_{\mathrm{t}-1}$ & & & & \\
Variable & $(\mathrm{LM}$ test statistic) & $\mathrm{T}_{\mathrm{B} 1}$ & & $\mathrm{~T}_{\mathrm{B} 2}$ & $\mathrm{k}$ & Result \\
\hline Stock price indices for Iran & -4.7498 & $\mathrm{Dec}-98\left(\lambda_{1}=0.153\right)$ & Jul-01 $\left(\lambda_{2}=0.352\right)$ & 10 & Unit root with & \\
$\left(\mathrm{P}_{\mathrm{It}}\right)$ & & $\mathrm{B} 1(\mathrm{t})$ & $\mathrm{D} 1(\mathrm{t})$ & $\mathrm{B} 2(\mathrm{t})$ & $\mathrm{D} 2(\mathrm{t})$ & Two breaks \\
& & $2.1042^{* *}$ & $-2.7232 * * *$ & -0.4547 & $1.9405^{* *}$ & \\
\hline
\end{tabular}

Source: The author's calculations.

Refer to the details explained for Table 1

Table 3. Unit root test for Interest Rates according to Lee and Strazicich $(2003 ; 2004)$ Two-Break (break in both intercept and trend) minimum LM Unit-Root Test

\begin{tabular}{|c|c|c|c|c|c|c|c|}
\hline Variable & $\begin{array}{l}\mathrm{S}_{\mathrm{t}-1} \\
\text { (LM test statistic) }\end{array}$ & $\mathrm{T}_{\mathrm{B} 1}$ & & $\mathrm{~T}_{\mathrm{B} 2}$ & & $\mathrm{k}$ & Result \\
\hline $\begin{array}{l}\text { Stock price indices for Iran } \\
\left(\mathrm{P}_{\mathrm{It}}\right)\end{array}$ & $-15.9719 * * *$ & $\begin{array}{l}\text { Jan-07 }\left(\lambda_{1}=0.533\right) \\
\text { B1 }(t) \\
0.9618\end{array}$ & $\begin{array}{l}\text { Sep-08 }\left(\lambda_{2}=0.8\right) \\
\text { D1 }(t) \\
-6.0835^{* * *}\end{array}$ & $\begin{array}{l}10 \\
\mathrm{~B} 2(\mathrm{t}) \\
-10.6824 * * *\end{array}$ & $\begin{array}{l}\text { Unit root with } \\
\text { D2(t) } \\
15.7984 * * *\end{array}$ & & Two breaks \\
\hline
\end{tabular}

Source: The author's calculations.

Details of this table is the same as Table 1 and 2 with the exception of the selected period of time, shorter than the first two tables, Dec-2003 to Nov-2009

$$
\begin{aligned}
& \Delta I n P_{I t}=\alpha_{I 0}+\sum_{i=1}^{P} \alpha_{P I 1} \Delta I n P_{I(t-i)}+\sum_{i=0}^{p} \alpha_{P I 2} \Delta I n P_{S(t-i)} \\
& +\sum_{i=0}^{p} \alpha_{P I 3} \Delta I n P_{K(t-i)}+p i=\sum_{i=0}^{p} \alpha_{P i 4} \Delta I n P_{U(t-i)} \\
& +\sum_{i=0}^{p} \alpha_{P I 5} \Delta I n P_{G(t-i)}+\sum_{i=0}^{p} \alpha_{P I 6} \Delta I n P_{J(t-i)}+\beta_{P I 1} \operatorname{In} P_{I(t-1)} \\
& +\beta_{P I 2} I n P_{S(t-1)}+\beta_{P I 3} \operatorname{In} P_{K(t-1)}+\beta_{P I 4} \operatorname{In} P_{U(t-1)}+\beta_{P I 5} \operatorname{In} P_{G(t-1)} \\
& +\beta_{P I 6} I n P_{J(t-1)}+\alpha_{P I S} D(T B)_{t}+\alpha_{P I 9} D U_{t}+\alpha P_{I 10} t+\varepsilon_{t}
\end{aligned}
$$

where, $\varepsilon$ is a vector of random error term and $\ln \mathrm{P}_{\mathrm{It}}, \ln \mathrm{P}_{\mathrm{St}}, \ln$ $\mathrm{P}_{\mathrm{Kt}}, \ln \mathrm{P}_{\mathrm{Ut}}, \ln \mathrm{P}_{\mathrm{Gt}}$ and $\ln \mathrm{P}_{\mathrm{Jt}}$ are residuals for each selected countries' financial markets. Means we have applied the ARDL cointegration method which we set out earlier in this chapter but we should take into account the breaks. Hence, before applying the ARDL in order to consider all the breaks found to be significant in stationary test earlier, we run preliminary regressions. First stage regressions of the $\log$ price indices on the trend and the dummies (found to be significant in stationary test). We remove the effects of 
those trends and dummies and take the residuals of those equations analysed in ARDL. We consider residuals in ARDL rather than considering all the significant breaks for all the selected countries in ARDL which will consume large amount of degrees of freedom and will cause high colinearity that makes it impossible to process the ARDL.

Moreover, to solve the matter of high colinearity among the dummies we also tried to ignore the breaks in the ARDL process but we could not find any long-run relationship among the selected countries financial markets, suspicious regarding all the information provided in Chapter 2. Hence, in order to take into account different breaks in different series without facing to the colinearity problem, residuals are considered in ARDL.

Notably, Equation (18) is designed and estimated in the ARDL framework for all the selected financial markets (namely, money and foreign exchange rate) in turn where Iran financial markets are dependent variables in turn. Following the theoretical background of this method explained earlier in this study, F-statistic is computed in order to test the null hypothesis $\mathrm{H}_{0}: \mathrm{H}_{1}: \beta_{\mathrm{PI} 1}=$ $\beta_{\mathrm{PI} 2}=\beta_{\mathrm{PI} 3}=\beta_{\mathrm{PI} 4}=\beta_{\mathrm{PI} 5}=\beta_{\mathrm{PI} 6}=0$ and the alternative defined as $\mathrm{H}_{1}$ : $\beta_{\mathrm{PI} 1} \neq 0, \beta_{\mathrm{PI} 2} \neq 0, \beta_{\mathrm{PI} 3} \neq 0, \beta_{\mathrm{PI} 4} \neq 0, \beta_{\mathrm{PI} 5} \neq 0$, $\beta_{\text {PI } 6} \neq 0$. Similarly this hypotheses are applied for the foreign exchange and the money markets as well. Also bounds are computed automatically by Mfit 5 and were reported after estimation of the regression, means critical values are flexible based on the sample size.

Ultimately, application of the method and the achieved empirical results are reported as follows.

The ARDL cointegration approach is conducted by following the three steps, correspondingly. First, assessing the long-run relationship by using the bounds testing approach and Evaluating the Long-run and short-run elasticity as the second and the third steps, respectively.

The empirical results reported in the current section are based on the diagnostic test results. Diagnostic tests which are modified by Microfit are serial correlation, functional form, normality and heteroscedasticity. According to Laurenceson and Chai (2003), ECM has been shown to be robust against serial correlation and Alam and Ahmad (2010) is one of the most recent works which used this characteristics of ECM to assess the diagnostic test results. Moreover, this research is not in the risk of over-parameterization when sufficient numbers of data are available for each series (156 observation for stock price indices and exchange rate and 75 observations for interest rate). Therefore, checking the residuals of the individual equations in VAR for possible serial correlation is not necessary for this research. On the other hand, Pesaran and Pesaran (2009) indicated three solution for serial correlation such as importing dummy variables, increasing lag lengths of series and accounting non-linier effects in a model. Although the author is not worried about the serial correlation based on the above research characteristics mentioned, the dummies are included in models and also the author has found increasing the lag length could not solve the matter of serial correlation but just could decrease it insignificantly. Even though, increasing the lag length is not recommended by the model selection criteria or likelihood ratio test statistics as they may cause other side effects (Pesaran and Pesaran, 2009). Additionally, we are not worried about other diagnostic matters viz., the functional form and the normality when the monthly time series are conducted over the long period of time. Furthermore, the heteroscedasticity is resolved by Newey-West adjusted with Parzen weights as the author was worried about this matter which could affect the empirical results entirely.

Different lags are applied such as 4, 8 and 12, separately, to find out the most suited VAR order for the models. The Akaike (AIC) and the Schwarz Baysian Criterion (SBC) indicated the similar results of VAR by applying each lag length separately. 3 and 1 respectively for stock price indices, 3 and 1 for Exchange rate and 4 and 1 for interest rate. Following Pesaran and Pesaran (2009), the VAR order is determined in terms of Akaike (AIC) in the case that this research is not in the risk of overparameterization when sufficient numbers of data are available for each series (156 observation for stock price indices and exchange rates and 75 observations for interest rates). Importantly, checking the possibility of the matter of the serial correlation among the residual of the individual equations in VAR is not required in the mentioned case.

Analysis of integration of equity markets among the selected countries confirms existence of long-run relationship between the equity markets, basically $\mathrm{F}$ statistic is significant, F-statistic is non-standard, irrespective of the order of the integration of the regressors (familiar F-statistic for the joint significance of $\beta_{\mathrm{I} 1}, \beta_{\mathrm{I} 2}, \beta_{\mathrm{I} 3}, \beta_{\mathrm{I} 4}, \beta_{\mathrm{I} 5}$ and $\left.\beta_{\mathrm{I} 6}\right)$, refer to the model demonstrated earlier in subsection 4.2. Meaning that the calculated F-statistic is significant at five percent significant level and the null Hypothesis of no level effects among the variables is rejected. Note: if we find F-statistic between the lower and the upper bonds at five percent significant level we consider it as 'inconclusive' (insignificant in this research). However, Kremers et al. (1992) and Bahmani-Oskooee and Nasir (2004) believe when F-statistic is inconclusive, significance of the error correction term is still a useful way to establish the cointegration relationships. In contrast, this research is 
consistent at five percent significant level for confirming the significance of the F-statistic). In this model dependent variable is Iran equity market (as explained earlier in this study residuals are considered for all the selected countries' financial markets) and the right hand-side variables are Saudi Arabia, Kuwait, the U.S., Germany and Japan equity markets respectively. In the aforementioned model the right hand-side variables are delighted as the 'long-run forcing variables' for the enlightenment of the dependent variable, (Pesaran and Pesaran, 2009). Quantitative results reported in Table $\mathbf{4}$ are against several previous studies, namely Neaime (2005) (For more details on each approach mentioned in this section refer to the section where the previous literature is discussed) and Elyasiani and Zhao (2008), mentioning no long-run relationships among dev eloped and developing countries' equity markets.

Further analysis on computation of the long-run and short-run coefficients along with testing the significance of the lagged levels of the variables in the error correction form of the underlying ARDL showed that Iran equity market revert to the long-run equilibrium in one lag after receiving its own effects but diverge from long run equilibrium and never return after receiving effects from Japan.
In this normalized model on Iran equity market the AIC lag specification for $\operatorname{LP}_{\text {It }}$ is ARDL $(2,0,0,0,0,0)$ (Numbers in the bracket represent the lags of the variables).

Along with the long and short-run analyses, the error correction coefficient, ecm (-1) is -0.20669 with the correct sign and significant T-ratio that suggests the moderate speed of convergence to equilibrium after deviating from the equilibrium. Where the larger ecm(1 ), in absolute value, indicates the faster the economy's return to equilibrium (Pesaran and Pesaran, 2009).

Importantly, considering the matter of multicolli nearity among the selected countries' financial indices, in order to shed light on the integrated markets, Iran equity market is analysed with all the selected countries' equity markets individually and showed that it is significantly integrated with Saudi Arabia, Kuwait, Germany and Japan while it is close to be significantly integrated with the U.S. equity market (Iran equity market is integrated with the U.S. equity market at $10 \%$ significant level, residuals are considered in ARDL as explained earlier in this study).

Table 4. Result of cointegration test for the selected countries stock price indices, testing the Long-Run relationships among variables (Stock Price Indices) based on the F-Statistics

\begin{tabular}{|c|c|c|c|c|c|c|}
\hline $\begin{array}{l}\text { F (Dependent variable/All other } \\
\text { considered variables) UB }\end{array}$ & F-Statistic & Result & $\begin{array}{l}\text { 95\% LB (LB stands } \\
\text { for Lower Bound) }\end{array}$ & $\begin{array}{l}95 \% \text { UB (UB stands } \\
\text { for Upper Bound) }\end{array}$ & $90 \%$ LB & $90 \%$ \\
\hline $\begin{array}{l}\mathrm{F}\left(\mathrm{LP}_{\mathrm{It}} / \mathrm{LP}_{\mathrm{SAt}}, \mathrm{LP}_{\mathrm{Kt}},\right. \\
\left.\mathrm{LP}_{\mathrm{US}(\mathrm{NASDAQ})}, \mathrm{LP}_{\mathrm{Gt}}, \mathrm{LP}_{\mathrm{Jt}}\right)\end{array}$ & 3.4459 & $\begin{array}{l}\text { Null hypothesis } \\
\text { (The null Hypothesis } \\
\text { is no level effects }\end{array}$ & & & & \\
\hline $\mathrm{R}^{2} 0.79362 \bar{R}^{2} 0.78514$ & & $\begin{array}{l}\text { among variables) } \\
\text { is rejected }\end{array}$ & 2.1752 & 3.4241 & $1 . .8336$ & 2.9527 \\
\hline
\end{tabular}

DW Statistic 1.9943

- Critical value bounds are computed by stochastic simulations using 20000 replications (Mfit 0.5 result) and the lag length 3 is determined through Johans en approach according to Akaike (ACI) method when observations in the current research are quite sufficient to not to be worried about misspecification)

Source: The Author's calculations

Table 5. Results of Cointegration test for the middle east short-term interest rate testing the long-run relationships among variables (Exchange Rates) based on F-Statistics

\begin{tabular}{|c|c|c|c|c|c|c|}
\hline $\begin{array}{l}\text { F(Dependen t variable/ } \\
\text { All other considered variables) }\end{array}$ & F-Statistic & Result & $95 \%$ LB & $95 \%$ UB & $90 \% \mathrm{LB}$ & $90 \%$ UB \\
\hline $\begin{array}{l}\mathrm{F}\left(\mathrm{LR}_{\mathrm{It}} / \mathrm{LR}_{\mathrm{St}}, \mathrm{LR}_{\mathrm{Kt}},\right. \\
\left.\mathrm{LR}_{\mathrm{Ut}}, \mathrm{LR}_{\mathrm{Gt}}, \mathrm{LR}_{\mathrm{Jt}}\right)\end{array}$ & $8.2584 * * *$ & $\begin{array}{l}\text { Null hypothesis } \\
\text { (The null Hypothesis is no } \\
\text { level effects among variables) }\end{array}$ & 2.2479 & 3.5889 & 1.8851 & 3.0833 \\
\hline $\begin{array}{l}\mathrm{R}^{2} 0.79552, \overline{\mathrm{R}}^{2} 0.71934 \\
\mathrm{DW} \text { Statistic } 2.2332\end{array}$ & & is rejected & & & & \\
\hline
\end{tabular}

- Critical value bound s are computed by stochastic si mulations using 20000 replications (Mfit 0.5 result) and the lag length 3 is determined through Johanse $\mathrm{n}$ approach according to Akaike (ACI) method w hen the observations in the current research are quite sufficient to not to be worried about $\mathrm{m}$ isspecification

Source: The Author's calculations 
Table 6. Results of cointegration test for the middle east foreign exchange rate testing the long-run relationship among Variables (Interest Rates) According to F-Statistics

\begin{tabular}{|c|c|c|c|c|c|c|}
\hline $\begin{array}{l}\text { F(Dependent variable/ } \\
\text { All other considered variables) }\end{array}$ & F-Statistic & Result & $95 \%$ LB & $95 \%$ UB & $90 \%$ LB & $90 \% \mathrm{UB}$ \\
\hline $\begin{array}{l}\mathrm{F}\left(\mathrm{LE}_{\mathrm{It}} / \mathrm{LE}_{\mathrm{St}}, \mathrm{LE}_{\mathrm{Kt}}, \mathrm{LE}_{\mathrm{U}(\mathrm{CPI}) \mathrm{t}},\right. \\
\mathrm{LE}_{\mathrm{G}(\mathrm{CPI}) \mathrm{t}, \mathrm{LE}} \mathrm{J}_{\mathrm{J}(\mathrm{CPI}) \mathrm{t}} \\
\mathrm{R}^{2} 0.84632, \overline{\mathrm{R}}^{2} 0.83550 \\
\text { DW Statistic } 2.0089\end{array}$ & 1.5881 & $\begin{array}{l}\text { Null hypothesis } \\
\text { (The null Hypothesis is no } \\
\text { level effects among variables) } \\
\text { is rejected }\end{array}$ & 2.1752 & 3.4241 & 1.8336 & 2.9527 \\
\hline
\end{tabular}

- Critical value bounds are computed by stochastic simulations using 20000 replications (Mfit 0.5 result) and the lag length 4 is determined through Johanse $\mathrm{n}$ approach according to Akaike (ACI) method when the observations in the current research are quite sufficient to not to be worried about $\mathrm{m}$ is specification.

Source: the Author's calculations

Moreover, significant long-run relationships are found between the selected countries money market. The quantitative results are reported in Table 5.

As discussed earlier based on significance of the Fstatistic, implying the existence of the long-run relationship between the selected countries' money markets, further exploration on the long-run coefficients and testing the significance of the lagged levels of the variables in the error correction form of the underlying A RDL are required. In that respect the model is normalized on Iran money market (as clarified earlier in this section we have taken residuals into account in ARDL). Results show that Iran money market does not receive its own effects; the AIC lag specification is ARDL $(4,3,4,4,0,0)$. Significance o $f$ the long-run coefficients and the lagged levels of the variables in the error correction form of the underlying ARDL is analyzed and the results indicate hat Saudi Arabia, Kuwait and U.S. have significant influencies on Iran money market.

Results show that Saudi Arabia is affecting Iran money market which means that Iran money market diverge from the long-run equilibrium, but the effects coming from Saudi Arabia will vanish after one and two lags and Iran money market will return to the long-run equilibrium (This is when signs for coefficients in the both long-run and error correction forms are not similar and coefficient in the err or correction form is less than one as when is bigger than one will diverge from the equilibrium). Moreover, effects coming from U.S. after two and three lags will die out directly and Iran money market will return to the long-run equilibrium. Ultimately, effects from Germany cause Iran money market to diverge from the long-run equilibrium and never return to the long run equilibrium (This is w hen signs for coefficients in the both long-run and error correction forms are similar).
The error correction coefficient in this model, ecm $(-1)$, is-0.89199 with the correct sign which suggests the moderate speed of convergence to equilibrium after deviating from the equilibrium, when it is statistically significant.

No related previous literature found in order to compare the results of the long-run relationship among the selected countries' money markets.

Ultimately, Table 6 is reporting the results for the selected countries' foreign exchange markets' long-run relations hip. Analysis of integration of foreign exchange markets among the selected countries confirms no long-run relationship between Iran and the selected countries. In this model dependent variable is Iran foreign exchange market and right hand-side variables are Saudi Arabia, Kuwait, the U.S., Germany and Japan foreign exchange markets respectively.

\section{CONCLUSION}

This study began from the argument of segmentation of Iranian financial markets from the rest of the world, however in the last three years privatization increased in Iranian financial markets as well as capitalization, FDI and equity prices (albeit there is a suspicion that equity prices have reached the bubble level (IMF, 2011b)). Also major focus of Iranian government over its fourth and fifth development plans (2005-2015) has been expanding foreign trades, attending in international markets actively and increasing the global integration. Importantly, according to IMF (2007), Iran has received significant spillover effects in recent years from neighborring financial markets, mostly from Saudi Arabia. Therefore, we decided to analyze Iran's integration within the Middle East and with the rest of the world to better understand Iran's financial development and provide information for policymakers and portfolio managers. The ARDL cointegration approach applied to analyse 
interdependencies among financial markets after conducting the (Lee and Strazicich, 2003; 2004), unit root test in order to analyze the stationary of the series.

We found that there is no significant interaction for Iranian foreign exchange market within the Middle East and with the rest of the world. But, results show that there are long-run relationships among Iran equity and money markets in turn with the other selected countries.

In sum, this study shows that Iran financial markets are neither fully integrated nor completely segmented within the Middle East and with the rest of the world, which immediately suggests the potential for international diversification. However, it is still controversial whether Iran should be considered as a good choice for international portfolio diversification based on its segregated nature.

In my next paper I will show that although Iranian equity and money markets are integrated in levels within the Middle East and with the rest of the world, they are not receiving any significant volatility spillover effects from foreign equity and money markets. On the other hand, I will illustrate that although Iranian foreign exchange market is not showing any integration in levels within the Middle East or with the rest of the world, it has received significant volatility spillover effects from foreign exchange markets. These findings shed light on the fact that it is possible that a country's financial markets not to be integrated in levels with other countries' financial markets, but still receive foreign volatility spillover effects and vise-versa.

\section{ACKNOWLEDGEMENT}

I thank my former supervisor Professor Ed. Wilson president of economic society of Australia (NSW) who gave a sole to the entire idea of writing this paper at the very early stages when I just started my $\mathrm{PhD}$ program over the period February 2010-January 2011. My next thank goes to my current supervisor professor Nicolaas Groenewold for all his useful comments and valuable and helpful guidance started from July 2011 to September 2012. In addition, my special thank goes to Professor melville Davies for his time spent on reviewing my paper and his helpful comments, also I appreciate all precious comments received from the participants of two seminars at the University of Western Australia hold in November 2011 and March 2012 respectively when I presented my paper. Importantly I am really grateful to the University of Western Australia for its financial supports.

\section{REFERENCES}

Agenor, P.R., 2003. Benefits and costs of international financial integration: Theory and facts. World Econo., 26: 1089-1118. DOI: 10.1111/1467-9701.00564

Akaike, H., 1973. Information theory and the extension of the maximum likelihood principle. Proceedings of the 2nd International Symposium on Information Theory. Petrov, B.N. and F. Csaki, (Eds.), Akadémiai Kiado, Budapest, pp: 267-271.

Akaike, H., 1974. A new look at the statistical identification model. IEEE Trans. Automatic Control, 19: 716-723. DOI: 10.1109/TAC.1974.1100705

Alam, S. and Q.M. Ahmed, 2010. Exchange rate volatility and Pakistan's import demand: An application of autoregressive distributed lag model. Int. Res. J. Finance Econo., 48: 7-22. DOI: 10.5539/ijef.v3n2p245

Bahmani-Oskooee, M. and A. Nasir, 2004. ARDL approach to test the productivity bais hypothesis. Rev. Develop. Econo., 8: 483-488. DOI: 10.1111/j.1467-9361.2004.00247.x

Bai, J. and P. Perron, 2003. Computation and analysis of multiple structural changes models. J. Applied Econo., 18: 1-22.

Bakri, A.K., A.M. Shabri and A.K.S. Ariffin, 2009. Financial integration between Indonesia and international markets: An application of ARDL bound testing approach. Proceedings of the 5th International GABER Conference Proceeding, (CP' 09), pp: 162-177.

Bekaert, G. and C. Harvey, 2002. Research in emerging markets finance: Looking to the future. Emerging Markets Rev., 3: 429-448. DOI: 10.1016/S09275398(02)00054-3

Bekaert, G., C.R. Harvey and A. NG, 2005. Market integration and contagion. J. Bus., 78: 32-69.

Bessler, D. and J. Yang, 2003. The structure of interdependence in international stock markets. J. Int. Money Finance, 22: 262-287. DOI: 10.1016/S0261-5606(02)00076-1

Dickey, D.A. and W.A. Fuller, 1979. Distribution of the estimators for autoregressive time series with a unit root. J. Am. Stati. Associat., 74: 427-431.

El-Gamal, M.A. and A.M. Jaffe, 2008. Energy, financial contagion and the dollar. working paper series, The Global Energy Market: Comprehensive Strategies to Meet Geopolitical and Financial Risks. 
Elliott, G., T.J. Rothenberg and J.H. Stock, 1996. Efficient tests for an autoregressive unit root. Econometrica, 64: 813-836.

Elyasiani, E. and W. Zhao, 2008. International interdependence of an emerging market: The case of Iran. Applied Econo., 40: 395-412. DOI: 10.1080/00036840600707027

Engle, R.F. and C.W.J. Granger, 1987. Cointegration and error correction: Representation, estimation and testing. Econometrica, 55: 251-276.

Fadhlaoui, K., M. Bellalah, A. Dherry and M. Zouaouii, 2009. An empirical examination of international diversification benefits in central European emerging equity markets. Int. J. Bus., 14: 163-173.

Goletti, F., R. Ahmad and N. Farid, 1995. Structural determinants of market integration: The case of rice markets in Bangeladesh. Develop. Econo., 33: 185-202.

Gregory, A.W. and B.E. Hansen, 1996. Residual-based tests for cointegration in models with regime shifts. J. Econo., 70: 99-126. DOI: 10.1016/03044076(69)41685-7

Hannan, E.J. and B.G. Quinn, 1979. The determination of the order of an autoregression. J. Royal Stati. Soc., 41: 190-195.

Hall, A., 1994. Testing for a unit root in time series with pretest data based model selection. J. Bus. Econo. Stati., 12: 461-70.

Higgins, M., T.H. Klitgaard and R. Lerman, 2006. Recycling petrodollars. Current Issues Econo. Finance, 12: 1-7.

IMF, 2011a. International Monetary Fund', no. 11/241, IMF Country Report 2010, 'International Monetary Fund, no. 10/74. pp: 1-32.

IMF, 2011b. Staff Report for the 2011 Article IV Consultation Information Annex, Prepared by Middle East and Central Asia Department, pp: 1-43.

IMF, 2007. The Multilateral Consultation on Global Imbalances. IMF staff-07/03.

Jackson, J.K., 2008. Foreign ownership of U.S. financial assets: implications of a withdrawal.

Johansen, S., 1991. Estimation and hypothesis testing of cointegration vectors in Gaussian vector autoregressive models. Econometrica, 56: 1551-1580.

Johansen, S., 1995. Likelihood-based inference in cointegration vector autoregressive models. Oxford University Press, 14: 517-524.

Johansen, S., 1988. Statistical analysis of cointegration vectors. J. Econo. Dynam. Control, 12: 231-254. DOI: 10.1016/0165-1889(88)90041-3

Johansen, S. and K. Juselius, 1990. Maximum likelihood estimation and inference on cointegration with application to the demand for money. Oxford Bull.
Econo. Stati., 52: 169-210. DOI: 10.1111/j.1468-0084.1990.mp52002003.x

Kremers, J., N. Ericson and J. Dolado, 1992. The power of cointegration test. Oxford Bull. Econo. Stati., 54: 325-343. DOI: 10.1111/j.1468-0084.1992.tb00005.x

Laurenceson, J. and J.C.H. Chai, 2003. Financial reform and economic development in China.

Lee, J. and M.C. Strazicich, 2001. Break point estimation and spurious rejections with endogenous unit root Tests. Oxford Bull. Econo. Stati., 63: 535-558. DOI: 10.1111/1468-0084.00234

Lee, J. and M.C. Strazicich, 2003. Minimum lagrange multiplier unit root test with two structural breaks. Rev. Econo. Stati., 85: 1082-1089. DOI: 10.1162/003465303772815961

Lee, J. and M.C. Strazicich, 2004. Minimum LM unit root test with one structural break. Appalachian State University.

Lumsdaine, R.L. and D.H. Papell, 1997. Multiple trend breaks and the unit root hypothesis. Rev. Econo. Stati., 79: 212-218.

Marashdeh, H., 2005. Stock market integration in the MENA region: An application of the ARDL bounds testing approach. University of Wollongong.

Narayan, P.K. and S. Popp, 2010. A new unit root test with two structural breaks in level and slope at unknown time. J. Applied Stati., 37: 1425-1438. DOI: $10.1080 / 02664760903039883$

Neaime, S., 2005. Financial market integration and macroeconomic volatility in the MENA region: An empirical investigation. Rev. Middle East Econo. Finance, 3: 231-255 DOI: $10.1080 / 14753680500407258$

Nunes, L., P. Newbold and C.M. Kuan, 1997. Testing for unit roots with breaks: Evidence on the great crash and the unit root hypothesis reconsidered. Oxford Bull. Econo. Stati., 59: 435-448. DOI: 10.1111/1468-0084.00076

Perron, P., 1989. The great cash, the oil price shock and the unit root hypothesis. Econometrica, 57: 1361-1401.

Perron, P., 1997. Further evidence on breaking trend functions in macroeconomic variables. J. Econo., 80: 355-85.

Perron, P. and T.J. Vogelsang 1992. Testing for a unit root in a time series with a changing mean: Corrections and extensions. J. Bus. Econo. Stati., 10: 467-470.

Pesaran, M.H., 1997. The role of economic theory in modelling the long-run. Econo. J., 107: 178-191.

Pesaran, M.H. and B. Pesaran, 2009. Time series econometrics. Oxford University Press. 
Pesaran, M.H. and B. Pesaran, 1997. Working with Microfit 4: Interactive econometric analysis. Oxford University Press.

Pesaran, M.H., Y. Shin and R.P. Smith, 2001. Bounds testing approaches to the analysis of level relationships. J. Applied Econo., 16: 289-326. DOI: 10.1002/jae.616

Pesaran, M.H. and Y. Shin, 1998. An auto regressive distributed lag modelling approach to cointegration analysis. Proceedings of the Econometrics and Economic Theory in the 20th Century: The Ranger Frisch Centennial Symposium, Storm, S., A. Holly and P. Diamond (Eds.), Cambridge, Cambridge University Press.

Pesaran, M.H., Y. Shin and R.P. Smith, 1996. Testing for the existence of a long-run relationship. University of Cambridge.

Pesaran, M.H. and R. Smith, 1998. Structural analysis of cointegration VARs. J. Econo. Surveys, 12: 471505. DOI: $10.1111 / 1467-6419.00065$

Pesaran, M.H. and R.P. Smith, 1985. Evaluation of macroeconometric models. Econo. Modeling, 2: 125-134. DOI: 10.1016/0264-9993(85)90018-5

Phylaktis, K. and F. Ravazzolo, 2005. Stock market linkages in emerging markets: Implications for international portfolio diversification. J. Int. Markets Institute. Money, 15: 91-106. DOI: 10.1016/j.intfin.2004.03.001

Prasad, E.S., 2011. Role reversal in global finance. Finance Develop., 48: 26-29.

Saikkonen, P. and H. Lutkepohl, 2000a. Testing for the cointegration rank of a VAR process with an intercept. Econo. Theory, 16: 373-406.

Saikkonen, P. and H. Lutkepohl 2000b. Testing for the cointegration rank of VAR process with structural breaks. J. Bus. Econo. Stati., 18: 451-464.

Saikkonen, P. and H. Lutkepohl, 2000c. Trend adjustment prior to testing for the cointegration rank of a vector autoregressive process. J. Time Series Analysis, 21: 435-456. DOI: 10.1111/14679892.00192
Schmidt, P. and P. Phillips, 1992. LM tests for a unit root in the presence of deterministic trends. Oxford Bull. Econo. Stati., 54: 257-287. DOI: 10.1111/j.1468-0084.1992.tb00002.x

Schwarz, G., 1978. Estimating the dimension of a model. Ann. Stati., 6: 461-464. DOI: 10.1214/aos/1176344136

Shin, K. and C.H. Sohn, 2006. Trade and financial integration in East Asia: Effects on co-movements. World Econo., 29: 1649-69. DOI: 10.1111/j.14679701.2006.00862.x

Soofi, A., 2008. Global financial integration and the MENA countries: Evidence from equity and money markets. East Econo. Finance, 4: 1-24. DOI: 10.2202/1475-3693.1102

Yuhn, K.H., 1997. Financial integration and market efficiency: Some international evidence from cointegration tests. Int. Econo. J., 11: 103-116. DOI: 10.1080/10168739700000013

Yu, J.S. and M.K. Hassan, 2008. Global and regional integration of the Middle East and North African (MENA) stock markets. Q. Rev. Econo. Finance, 48: 482-504. DOI: 10.1016/j.qref.2006.06.003

Yang, J., J.W. Kolari and I. Min, 2003. Stock market integration and financial crises: The case of Asia. Applied Financial Econo., 13: 477-486. DOI: 10.1080/09603100210161965

Wilson, E. and H. Marashdeh, 2007. Are Cointegrated Stock Prices Consistent with the Efficient Market Hypothesis?', Economic Record, 83: S87-93. DOI: 10.1111/j.1475-4932.2007.00409.x.

Zivot, E. and D.W.K. Andrews, 1992. Further evidence on the great crash, the oil price shock and the unit root hypothesis. J. Bus. Econo. Stati., 10: 251-70. DOI: $10.1198 / 073500102753410372$ 